\title{
Cî̂nCias Sociais e InVestigação Criminal: METODOLOGIA DA INVESTIGAÇÃO CRIMINAL NA LÓGICA DAS CIÊNCIAS SOCIAIS
}

\author{
Eliomar da Silva Pereira \\ Coordenação Escola Superior de Polícia \\ Academia Nacional de Polícia - Brasil
}

$$
\approx
$$

\begin{abstract}
Resumo
A investigação criminal se desenvolve lógica e pragmaticamente à forma de uma investigação científica. Além da possibilidade de aplicação de conhecimento científico, oriundo das ciências empíricas na investigação dos crimes, ela mesma se pode desenvolver segundo o método científico, seja em cada investigação criminal particular, mediante a aplicação de técnicas de pesquisa que são próprias à ciência (sobretudo técnicas qualitativas), seja pela generalização de certas conclusões encontradas no conjunto de investigações de casos comuns, para aplicação posterior em outras investigações particulares (tendente a uma abordagem quantitativa). É certo que, ao investigar-se o crime como fato do passado, a investigação se aproxima mais da pesquisa historiográfica, mas, ao passo que a sociedade se tem tornado mais complexa e dinâmica, a investigação se tem tornado igualmente mais uma pesquisa de fatos presentes, ainda em curso (como são os casos de criminalidade organizada, p. ex.), devendo desenvolver-se para além de cada investigação presente, com vistas a desenvolver conhecimento operativo para investigações futuras. Nesse contexto é que o modelo das ciências sociais em geral, e a sociologia em específico, parece ser o caminho mais propício a uma metodologia da investigação criminal. É nesse sentido que se vai expor o problema metodológico das ciências sociais, suas limitações teóricas e suas técnicas de pesquisa, como forma de demonstrar a proximidade existente com as práticas de investigação criminal e a possibilidade de uma metodologia científica para ela, como uma forma particular de ciência social. Em síntese, trata-se de parcela de estudo mais amplo que pretende demonstrar as relações e proximidades entre investigação criminal e pesquisa científica.
\end{abstract}

PALAVRAS-CHAVE: método científico; sociologia de ação; investigação-ação; técnicas de pesquisa. 


\section{INTRODUÇÃO: A LÓGICA DAS CIÊNCIAS SOCIAIS}

As ciências sociais, especialmente a sociologia, nascem com a proposta de descobrirem "leis sociais", a partir da observação de fatos sociais para estabelecer-lhes as ligações causais ${ }^{2}$ e chegar a generalizações teóricas, tal como as ciências naturais. Ainda hoje há quem sustente ser essa a tarefa das ciências sociais, embora reconheça uma limitação em virtude do estágio científico, ou do objeto de pesquisa ${ }^{3}$.

Noutro rumo, tem-se sustentado, a partir das ideias de W. Dilthey ${ }^{4}$, que se devem distinguir as ciências naturais (de explicação causal) das ciências culturais (de interpretação ou compreensão). Mais detalhadamente, partindo dessa distinção, fala-se que o conhecimento humano procede ou por generalização das várias coisas pelos seus aspectos comuns, ou por individualização, pela consideração de várias coisas por seus aspectos particulares (BARATA, 1998, p. 23 e ss).

Essa dissensão (não entre haver duas espécies de ciências, mas sobre a ciência social ter ou não a mesma estrutura da ciência natural) instaura nas ciências sociais dois caminhos, o naturalismo e o historicismo 5 , tão bem explicado por Karl Popper (1957) que demonstra em que sentido cada um está correto e incorreto, segundo sua perspectiva falsificacionista da ciência. $\mathrm{Na}$ raiz dessa querela, segundo se tem observado (POPPER, 1976, p. 17), há uma equivocada visão das ciências naturais, fruto de um ingênuo indutivismo, contra o qual Karl Popper apresentou o falsificacionismo e o método hipotético-dedutivo como a lógica das pesquisas científicas.

Segundo Popper (1976, p. 16), em A lógica das ciências sociais, com base nessa premissa, "o método das ciências sociais, como aquele das ciências naturais, consiste em experimentar possíveis soluções para certos problemas; os problemas com os quais iniciam-se nossas investigações e aqueles que surgem durante a investigação". Quando Popper se refere a método, refere-se ao contexto lógico de justificação do conhecimento científico, em separado do

1 Nesse sentido, encontram-se as leis da evolução social de Comte (cf. Bottomore, 1971, p. 32).

2 Nesse sentido, é a opinião de Durkehin sobre a tarefa do sociológico (cf. Bottomore, 1971, p. 33, nota 8)

3 Cf. nesse sentido, Bottomore, 1971, p. 33.

4 Cf. Barata, 1998, p. 15.

5 Ressalte-se que o que se relata aqui é a síntese rudimentar de um problema epistemológico muito mais complexo. 
contexto de descoberta das técnicas de pesquisa. Popper (1976, p. 32; 1957, p. 137) refere-se assim a uma "lógica situacional", como a lógica apropriada à pesquisa social, em que os dados da realidade são considerados como elementos da situação, permitindo compreender ações dos sujeitos em sentido objetivo, como objetos situacionais. A essa lógica acresce a ideia de verdade aproximada que se deve perseguir pela ciência. Em complemento, Popper (1957, p. 108) se refere à necessária distinção que se deve fazer entre "leis" e "tendências", pois "as leis e as tendências são coisas radicalmente diferentes". A questão é que, segundo uma lógica situacional, a tendência de uma situação histórica particular não nos leva a uma lei universal inexorável ${ }^{6}$. Apesar disso, segundo Popper (1976, p. 32), "podem possuir um conteúdo verdadeiro considerável e podem, no sentido estritamente lógico, ser boas aproximações da verdade melhores do que outras explicações testáveis".

Apesar desse problema metodológico, isso não tem impedido a sociologia de recorrer a métodos variados, alternativos, e avançar em sua afirmação científica. Dessa forma, segundo T. Bottomore (1971, p. 53 e ss), tem-se visto proliferar pesquisas com recurso a variadas abordagens, como a histórica, comparativa, descritiva, estruturalista e funcionalista. Ainda no âmbito do problema metodológico e sua diversidade, Bottomore (ibidem, p. 66) se refere a uma sociologia formal, em que se considera a própria sociologia como um novo método, "uma nova forma de olhar os fatos" que já teriam sido tratados por outras ciências.

Em conclusão ao problema do método, T. Bottomore (ibidem, p. 70 e ss) considera que uma disciplina é científica por seus métodos e intenções. Quanto ao método, são características importante ocupar-se de fatos (não de juízos) e trazer provas empíricas a respeito desses fatos afirmados, de uma forma objetiva (no sentido de que qualquer um pode avaliar a afirmação segundo a prova). Quanto à intenção, a sociologia (como qualquer ciência social), deve visar a uma descrição exata, por análise de propriedades e relações entre fenômenos sociais, e pretender uma explicação por formulação de declarações gerais. É nesse ponto que a sociologia se apresenta com certas particularidades, pois ela não apresenta uma teoria geral aceita de forma generalizada, mas apenas de forma limitada, ou de tipos diversos dos que se observam e perseguem nas ciências naturais.

6 O que está por trás de uma explicação nesses termos não é uma questão de causalidade, mas de condicionalidade, segundo a qual, em determinadas condições $\mathrm{X}$, há uma tendência para $\mathrm{Y}$, o que, embora se torne algo limitado, tem a vantagem de reconhecer os limites do conhecimento sociológico e avançar a partir dele. 
Entre os diversos tipos de generalizações, na sociologia, encontramse certas "correlações empíricas entre fenômenos sociais concretos"; "generalizações formulando as condições sob as quais as instituições ou outras formações sociais surgem", ou "afirmando que as modificações em determinadas instituições estão regularmente associadas às modificações em outras instituições”, entre outras várias (cf. BOTTOMORE, 1987, p. 37 e ss). Além de generalização, encontram-se conceptualizações (como é o caso de conceitos como estrutura social, ideologia, burocracia etc.) e esquemas de classificações (como de grupos, ações etc.) muito produtivas.

A tudo isso - problema metodológico e limitações teóricas - acresce-se a questão das técnicas de pesquisa e a discussão em torno dos conflitos entre abordagem quantitativa e qualitativa, que fazem da sociologia um âmbito de saber ainda incerto, conquanto persista na sua afirmação como ciência, e assim como exemplo apto a fornecer modelos diversos de pesquisa que interessam a uma metodologia de investigação criminal.

\section{SOCIOLOGIA DE AÇÃO E INVESTIGAÇÃO-AÇÃO}

Tendo em consideração o problema metodológico da sociologia, pode-se entender porque "existem diferentes maneiras de abordar a realidade, que são outros tantos modelos de investigação, de tradições de pensamento ou ainda de problemáticas gerais..." - é essa a advertência que nos fazem Michel de Coster e Bernadette Bawin-Legros (1996), ao considerar que de uma forma sucinta podemos observar duas tradições, ou paradigmas, de investigação científica em sociologia: um determinista, outro da ação ou interação.

O paradigma determinista (em que se encaixariam as tradições funcionalista e estruturalista) pode ser entendido a partir de duas ideias fundamentais - de que todo fato social se explica por fenômenos que lhe são anteriores, e que por ser exterior é o que orienta a ação dos indivíduos. $\mathrm{O}$ paradigma da ação e da interação (em que se encaixariam tradições de abordagem estratégica e individualismo metodológico), por sua vez, nasce como reação à concepção positiva das ciências sociais como ciências de fatos objetivos, tendendo a considerar ação dos indivíduos como constitutivos dos fatos sociais (COSTER; BAWIN-LEGROS, 1996, p. 82 e 95) 7 . É precisa-

7 O autor considera a possiblidade de conciliação entre os paradigmas, pois "nenhum paradigma tem o monopólio da explicação". Em síntese, segundo ele, "se, com efeito, por um lado, parece que a sociedade modela o homem, por outro, é o homem que modela a sociedade, de modo que cada forma 
mente deste último contexto que parte uma sociologia de ação, que vamos expor sucintamente como um modelo propício a fazer despertar as relações que existem entre investigação científica sociológica e investigação criminal científica, sobretudo a partir do conceito de investigação-ação.

A sociologia de ação, ou de intervenção, tem sido oposta a uma sociologia acadêmica, apesar de coexistirem as duas perspectivas em pesquisas de terreno de variados campos profissionais. É nessa sociologia de campo que, segundo Isabel Guerra (2002, p. 10), deram-se os primeiros passos de uma investigação-ação, em trabalhos etnológicos especialmente, mas a sociedade industrial e urbanizada também sentiu a necessidade de tal perspectiva de investigação sociológica, a exemplo dos trabalhos da Escola de Chicago ${ }^{8}$. Com isso, passa-se a considerar a cidade como um laboratório natural das ciências sociais que tem por objetivo a solução de problemas muito pontuais (GUERRA, 2002, p. 12).

Por trás da ideia de investigação-ação há toda uma discussão epistemológica que se desenvolve a respeito das relações entre o sistema social e os autores, dando ensejo a paradigmas de pesquisa discordantes e variadas perspectivas metodológicas, como se referiu acima sucintamente 9 . Dessas perspectivas postas em confronto, surge uma interrogação acerca da relação entre conhecimento e ação. É nesse contexto que se colocam certas questões às metodologias tradicionais, tais como a necessidade de "compreensão do sujeito como ator capaz de racionalidade e de escolha" e de "entendimento das relações sociais como relações de poder" (GUERRA, 2002, p. 39). A tais questões se apresenta a investigação-ação, epistemologicamente, no sentido de uma redefinição do conhecimento científico através de uma concepção pragmática.

Nesse sentido, entende-se que "as metodologias de investigação-ação apresentem como elemento fulcral da estratégia de conhecimento a relação

de abordagem insiste numa das duas faces de uma mesma realidade" (1996, p. 109).

8 Pontue-se que alguns trabalhos da Escola de Chicago são especialmente conhecidos no campo da criminologia sociológica, ou sociologia do crime. Outro marco, e por muitos considerado o fundador da pesquisa-ação, são os trabalhos de Kurt Lewin, baseados em dinâmicas de grupo, destinados não a produzir conhecimento para depois ser aplicado por decisões políticas, mas a atuarem diretamente no problema - daí chamar-se muito constantemente de investigação operacional. Isabel Guerra (2002, p. 55), contudo, considera que é nos trabalhos de Dewey, no campo da educação, que se deve situar a origem da investigação-ação.

9 Entre essas perspectivas, que não vamos desenvolver aqui, mas são relevantes para a compreensão do tema, encontram-se o individualismo metodológico de Boudon, a análise estratégica de Grozier e a teoria da ação de Touraine. Para uma visão geral dessas perspectivas, cf. Guerra, 2002, 21 e ss; Coster, 1996 , p. 81 e ss. 
entre o cientista e o seu objeto de estudo (...), tendo em vista a mudança de uma situação dada para outra colectivamente desejada" (GUERRA, 2002, p. 43) ${ }^{10}$. Trata-se, assim, de uma postura sociológica que pretende reequacionar a relação entre ação e conhecimento, aprofundando as relações entre teoria e prática, em recusa a uma concepção contemplativa da ciência ${ }^{11}$. Nessa perspectiva de investigação, aceita-se que a realidade é anterior à teoria, a teoria é um meio, não um fim, logo “a teoria não é a ciência, é apenas um quadro hipotético de representação da realidade que se verá verificado no confronto com a empiria” (GUERRA, 2002, p. 45).

Nesse ponto, é comum oporem-se questões acerca da ética do conhecimento, pois fica evidente que a epistemologia da ciência é atravessada por opções ideológicas. Mas a relação inversa também é igualmente controversa, pois acreditar que a partir da ciência podemos identificar valores (no mundo de ideias a priori), seria incorrer no problema que Hume já advertia - não podemos deriva do ser o dever-ser. A essa questão, Henri Atlan (apud GUERRA, 2002, p. 48) parece nos dar uma boa proposta: "Não é a partir da ciência que se pode reformar uma ideia de homem e de sociedade, mas será sem dúvida a partir de uma ideia de homem e de sociedade que se pode utilizar a ciência ao seu serviço"12.

Assim, com a investigação-ação instaura-se uma metodologia diversa da ciência. É uma metodologia que, em comparação com o positivismo clássico, oriundo de uma visão das ciências naturais, possui características muito próprias. Em relação ao tipo de generalização, não é universal e independente do contexto, mas limitada e dependente. Quanto aos fins epistemológicos, não pretende predizer acontecimentos, mas construir planos de intervenção que permitam atingir objetivos visados. Quanto ao tratamento de informações colhidas, os casos individuais podem ser fontes suficientes de conhecimento. Quanto à tomada de posição sobre valores, os métodos

10 Veja-se que nessa concepção se pode identificar a definição de investigação proposta por Dewey, em sua "Lógica: Teoria da Investigação".

11 Ou seja, "mais do que correntes teóricas, trata-se, sobretudo, de posturas de investigação - apelidadas de investigação-acção - que procuram abranger um conjunto de experiências práticas desenvolvidas por vários autores, e relativamente distintas entre si, mas enquadradas no mesmo propósito de conhecer a realidade para a transformar, assumindo assim uma concepção pragmática da realidade social” (GUERRA, 2002, p. 43). Perceba-se que, sob essa perspectiva, as práticas de investigação criminal se encaixam facilmente nessa concepção de pesquisa científica.

12 Essa é, aliás, a via mais adequada quando nos colocamos em uma investigação criminal, em que se devem dirigir as ações segundo valores fundamentais (os direitos e garantias do homem), devendo qualquer ideia de ciência ser dirigida a partir deles como premissas do conhecimento e da ação. 
não são neutros, pois se desenvolvem em redes sociais e atualizam o potencial humano (GUERRA, 2002, p. 54). Com esses pressupostos, entre outros tantos que caracterizam a investigação-ação, essa metodologia encontra uma pluralidade de campos de aplicação ${ }^{13}$, entre os quais entendemos por situar a investigação criminal.

Quanto às técnicas dessa metodologia, utilizam-se todas as disponíveis nas ciências sociais, privilegiadas as qualitativas, sob uma perspectiva indutiva, que tentam teorizar a partir de informações empíricas, colhidas no campo, no terreno de ação, a partir de problemas que se colocam, na tentativa de resolvê-los, e para os quais a teoria se pretende voltar. Sobretudo, considera-se que há uma relação inevitável entre epistemologia e axiologia. Daí porque se admite que "a investigação-acção é uma metodologia ambiciosa que pretende conter todos os ingredientes da investigação e, mais ainda, os ingredientes da acção" (GUERRA, 2002, p. 75). Pois se trata de conhecimento produzido em confronto direto com o real, tentando transformá-lo, com desconstrução da ideia do papel do "especialista social". Assim, "a sociologia da intervenção produz-se muitas vezes à margem do sistema, junto de grupos e organizações em crise, sendo uma sociologia periférica (...) e não gozando de um grande reconhecimento pelas academias, pelo que também sofre de algumas debilidades metodológicas e técnicas" (GUERRA, 2002, p. 75) ${ }^{14}$.

\section{A PESQUISA QUALITATIVA NA INVESTIGAÇÃO: OBSERVAÇÃO E ENTREVISTA}

No campo das ciências sociais, manuais de investigação, ao tratarem dos métodos de recolhas de informações, referem-se à observação e à entrevista como duas das principais técnicas qualitativas (QUIVY e CAMPENHOUDT, 1995, p. 186 e ss) ${ }^{15}$. Essas técnicas se encontram, igualmente, entre as mais comuns na investigação criminal. Certo é, contudo, que há par-

13 Para uma visão desse diversos campos, cf. Guerra, 2002, p. 60.

14 No Brasil,essaé exatamente a situação das organizações policiais responsáveis pela investigação criminal, na relação com a sociologia acadêmica que, a partir de uma visão sempre externa de desconstrução da segurança publica, é incapaz de adentrar nos grandes problemas reais das instituições e construir novos modelos de ação. E ao serem confrontadas tais sociologias com a busca das instituições policiais pelo desenvolvimento de uma ciência própria, consideram ser impossível falar de uma ciência policial.

15 Ao lado dessas, encontra-se ainda o inquérito por questionário (QUIVY e CAPENHOUDT, 1995) que somente em situações muito particulares poderia ser utilizado na área da investigação criminal, mas tendo em vista outra espécie de questão não diretamente relacionada a um caso concreto investigado. Por isso, deixamo-lo de lado inicialmente, mas não descartamos em absoluto sua utilização. 
ticularidades nesse campo que fazem da observação e da entrevista uma técnica muito diferente do que se compreende nas ciências sociais em geral. Mas alguns pontos são tão comuns, e certos problemas são partilhados por ambos os campos, que é inevitável, e até é desejável, que a investigação criminal se aproveite de estudos já desenvolvidos no campo das ciências sociais a respeito dessas técnicas ${ }^{16}$.

Entre as principais particularidades que se devem observar no campo da investigação criminal, os limites jurídicos condicionantes dos direitos fundamentais talvez seja o mais importante. Com efeito, toda técnica de recolha de dados em sentido científico, que se possa transportar ao âmbito da investigação criminal, encontra nessa um condicionamento ético muito particular, que limita mesmo a persecução de uma verdade fática, em favor da valorização do direito dos investigados. Essa é uma barreira intransponível da investigação como pesquisa, mas é dentro desses limites que a potencialização das técnicas deve ser desenvolvida. Não obstante, as modalidades de observação e entrevista encontram na investigação uma variedade de que talvez nenhuma outra investigação científica se possa beneficiar, como são as técnicas de interceptação telefônica, para ficarmos com um exemplo corriqueiro.

A observação, como técnica de recolha de informação nas ciências sociais, possui vários sentidos, mas "no sentido mais restrito e melhor delimitado, a observação consiste em estar presente e envolvido numa situação social para registrar e interpretar, procurando não modificá-la” (PERETZ, 1998, p. 13). Trata-se de definição que aproveita à investigação criminal. É uma técnica que tem como objetivo encontrar, na sociologia, um significado para os dados recolhidos, a fim de classificá-los. Na investigação criminal, o sentido tem um parâmetro muito delimitado na teoria dos tipos penais. Dentre as espécies de observação, pode-se ainda encontrar um paralelo entre as formas direta, indireta e participante da sociologia com as diversas formas de observação que se encontram na investigação criminal, a exemplo da vigilância, da gravação de imagens e do agente infiltrado ${ }^{17}$. Esse em específico

16 Um estudo relevante, exclusivamente dedicado à observação, encontra-se em Henri Peretz, Método em Sociologia: a observação, em que o autor estrutura a técnica a partir de três atividades indissociáveis - a forma de interação social, a atividade de observação e o registro dos dados observados. Essa etapa, em específico, teria grande utilidade às práticas de investigação criminal, na qual os agentes não adquiriram ainda o costume científico de relato do observado. Isso, em parte, decorre de uma visão muito difundida que limita o científico ao experimento.

17 Algumas técnicas, contudo, parecem não se enquadrar muito facilmente na observação nem na entrevista. É o caso da interceptação telefônica que, embora se refira a dados verbais (não visuais, como em geral são as formas de observação), tem a característica própria da observação, por não interferir na situação. 
encontra uma aproximação muito forte com a observação participante, com vantagens metodológicas igualmente relevantes, pois exclui em absoluto o conhecimento da pesquisa pelo pesquisado.

Quanto à entrevista, na investigação criminal essa técnica encontra, para além de todos os problemas comuns às ciências sociais, todo um conjunto de problemas que decorrem da especial situação pesquisada - a existência de um crime, a respeito do qual se procura seu autor. Nesse sentido, é aceitável que a técnica exija uma atenção redobrada na investigação criminal, mas as questões suscitadas em sociologia podem ser um bom ponto de partida para estudos mais específicos ${ }^{18}$. Apesar da relevância dessa técnica na investigação criminal, assim como nas ciências sociais, os pesquisadores tendem a dedicar pouca atenção a ela (FODDY, 1993). Mas sua sistematização em torno de um modelo de entrevista, como técnica de pesquisa fundada em certos pressupostos básicos da psicologia, com uso de tecnologia de colheita (gravadores de voz) e redação de relatório, pode contribuir para a qualidade científica das investigações criminais.

\section{ANÁlise de CONTEÚDO: EM DIREÇÃo AO QUANTITATIVO}

Além da observação e entrevista, como técnicas de recolha de dados, na investigação criminal, assim como nas pesquisas sociais, é comum se recolherem documentos vários em complemento às informações. E ao final (talvez não tanto na sociologia, mas na investigação criminal em sua totalidade), sejam os dados verbais (entrevistas), sejam os visuais (observações), tudo acaba por ser reduzido a um conjunto de documentos, que se juntam aos demais documentos existentes anteriormente à investigação ${ }^{19}$. No conjunto, todas as informações exigem uma outra etapa, comum tanto às pesquisas científicas, quanto às investigações criminais, que é a de análise da informação (QUIVY e CAMPENHOUDT, 1995, 211 e ss). É nesse contexto que a análise de conteúdo se pode apresentar como uma técnica relevante à investigação.

18 Um bom estudo acerca da entrevista se encontra na obra Como Perguntar: Teoria e Prática da Construção de Perguntas em Entrevistas e Questionários, de William Foddy (1993), em que o autor declaradamente assume o interacionismo simbólico como quadro teórico de fundo para o desenvolvimento de seu estudo (p. 26). Segundo ele, "a mais básica implicação da teoria do para as situações de investigação traduz-se na hipótese de que o significado atribuído pelos sujeitos aos actos sociais é produzido no interior da própria relação em que esses actos ocorrem" (p. 23).

19 No direito processual brasileiro, aliás, o conceito jurídico de documento abrange tudo quanto seja registrado em um meio físico em condições de ser consultado, conferido, confrontado ou contraditado. 
A análise de conteúdo parece assumir, contudo, uma natureza dúplice. Tanto pode ser realizada em um sentido quantitativo, como em um sentido qualitativo (QUIVY e CAMPENHOUDT, 1995, p. 227). Nesse ponto, para cada investigação criminal em particular, interessa-nos a análise qualitativa ${ }^{20}$. A análise de conteúdo incide sobre mensagens variadas, é um procedimento de análise de material escrito, independente de sua origem, que pode ser desde dados de entrevistas, até os produzidos por terceiros (FLICK, 2002, p. 193). As questóes, contudo, que se colocam no campo das ciências sociais não são as que exatamente interessam à investigação criminal de casos concretos, mas pode interessar a identificação de certos padrões relevantes a orientação de investigações futuras. O importante é ter o domínio técnico das várias formas de análise sugerida pelos teóricos (sintetizadora, explicativa, estruturante $)^{21}$ e identificar os problemas da investigação criminal para os quais essas técnicas dispõe de uma possível resposta 22 .

\section{CONCLUSÃO: PADRÕES E MEDIDAS POSSÍVEIS}

As abordagens quantitativas não estão em absoluto descartadas de uma metodologia da investigação criminal. A questão é que o método quantitativo serve a problemas outros que o qualitativo tende a responder. Mas se partirmos dos dados estatísticos que são produzidos pelas diversas investigações - e mais que isso, se passarmos a produzir dados estatísticos dirigidos a certas questões não levadas em consideração em geral - podemos chegar a certas generalizações baseadas em medidas, como qualquer outra ciência. E se tais dados forem trabalhados a partir de programas e tecnologias de informação, são variadas as possibilidades de extrair padróes com medidas muito bem delimitadas. O problema, sob essa perspectiva, é estabelecer o que se pretende com um tal procedimento, em que sentido seus resultados podem interessar e aproveitar às investigações criminais em particular e de que forma tudo isso pode ser institucionalizado pelas organizações investidas na competência de investigar e instrumentalizado de forma que essa instância seja compatível

20 A análise quantitativa não pode ser de todo excluída do nosso interesse científico, conjuntamente com certas análises estatísticas, igualmente relevantes para a investigação criminal, mas no âmbito de outra ordem de questões.

21 A classificação é de Uwe Flick, Métodos Qualitativos na Investigação Científica, onde o autor apresenta outros variados métodos de codificação e categorização.

22 Uma possibilidade que se pode vislumbrar é a análise do conteúdo de diversos inquéritos investigativos, visando a extrair padrões de modus operandi de certos crimes em conexão com modos de prová-los. 
com os problemas mais corriqueiros e imediatos das práticas de investigação. Mas não temos dúvida de que é possível trabalhar com medidas e generalizações fundamentadas em estatísticas.

Enquanto um problema qualitativo pode pretender identificar padrões de investigação, a partir de padrões de modus operandi relativos a certos e determinados crimes, visando a orientar a colheita de provas por quem investiga na prática, outra ordem de problemas se pode colocar a quem compete não investigar, mas organizar os diversos setores (delegacias, p. ex.), em função do tipo e quantidade de crimes que se observam em dado território e em certo período. Ora, em tais casos, torna-se adequado falar em uma análise estatística de dados especificamente referidos a medidas, não a padrões de crime.

Podemos falar, assim, de inquérito de inquéritos - inquérito no sentido de pesquisa social, a partir de um conjunto de dados e resultados obtidos em inquéritos investigativos particulares, reunidos segundo certas classificações estipuladas. Seja para estabelecer padrões, seja para estabelecer medidas ${ }^{23}$.

Em síntese, assim como a sociologia surge segundo uma visão de ciência que se foi modificando e multiplicando em diversidades metodológicas, sem ainda hoje chegar a conclusões únicas a respeito de seus problemas, não se deve esperar que uma possível ciência de investigação criminal se ponha de uma vez, com todas suas questões já definidas. Tal pretensão seria exatamente o inverso do pressuposto de que partimos, no sentido de que existem concepções demais de ciência para que queiramos construir alguma fundada em uma ideia unitária. Como nos adverte os metodólogos, "o desenvolvimento da ciência deve caminhar a par com o do método sendo que as fragilidades da autonomia de cada área científica podem entroncar a montante nas das suas técnicas" (ESPÍRITO SANTO, 2010, p. 8).

Eliomar da Silva Pereira

Mestrando em Ciências Policiais (Criminologia e InvestigaÇão Criminal), no Instituto Superior de Ciências Policiais E Segurança Interna (ISCPSi, Lisboa, Portugal); Especialista em Ciências Criminais; Professor e Pesguisador na Academia Nacional de Polícia; Delegado de Polícia Federal (Brasília-DF).

E-MAIL: ELIOMAR.ESP@DPF.GOV.BR

23 Quanto aos inquéritos quantitativos, Boudon (1971, p. 41) os define como "aqueles que permitem recolher, num conjunto de elementos, informações comparáveis entre esses elementos. Esta comparação de informações possibilita, em seguida, a inumeração e, mais geralmente, a análise quantitativa dos dados. A condição necessária para a aplicação dos métodos quantitativos é que a observação incida sobre um conjunto de elementos, de certa maneira comparáveis." 


\section{REFERÊNCIAS}

ALBARELLO, Luc et al. (1995). Práticas e Métodos de Investigação em Ciências Sociais - Lisboa: Gradiva, 2005.

BARATA, Óscar Soares. Introdução às Ciências Sociais. Primeiro Volume - Lisboa Bertrand, 1998.

BOTTOMORE, T. B. (1971). Introdução à Sociologia. Rio de Janeiro: Editora Guanabara, 1987.

BOUDON, Raymond (1971). Os métodos em Sociologia. Lisboa: Rolim, 1990.

COSTER, Michel de; BAWIN-LEGROS, Bernadette (1996). Introdução à Sociologia. Lisboa: Editorial Estampa, 1998.

ESPÍRITO SANTO, Paula (2010). Introdução à Metodologia das Ciências Sociais. Lisboa: Edições Sílabo.

FLICK, Uwe (2002). Métodos Qualitativos na Investigação Científica. Lisboa: Monitor, 2005.

FODDY, William (1993). Como perguntar. Teoria e prática da construção de perguntas em entrevistas e questionários. Oeiras: Celta, 1996.

GUERRA, Isabel Carvalho. Fundamentos e Processos de Uma Sociologia de Acção. O Planeamento em Ciências Sociais. Estoril: Princípia, 2002.

PERETZ, Henri (1998). Método em Sociologia [A observação]. Lisboa: Temas e Debates, 2000.

POPPER, Karl (1957). A Pobreza do Historicismo Lisboa: Esfera do Caos, 2007.

POPPER, Karl (1976). A Lógica das Ciências Sociais. Rio de Janeiro: Tempo Brasileiro, 2004.

QUIVY, Raymond; CAMPENHOUDT, Luc Van (1995). Manual de Investigação em Ciências Sociais. Lisboa: Gradiva, 2008.

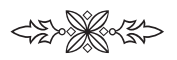

